\title{
Antegrade versus retrograde cerebral perfusion for hemiarch replacement with deep hypothermic circulatory arrest: Does it matter? A propensity-matched analysis
}

\author{
Asvin M. Ganapathi, MD, Jennifer M. Hanna, MD, MBA, Matthew A. Schechter, MD, \\ Brian R. Englum, MD, Anthony W. Castleberry, MD, MMCi, Jeffrey G. Gaca, MD, and \\ G. Chad Hughes, MD
}

\begin{abstract}
Objective: The choice of cerebral perfusion strategy for aortic arch surgery has been debated, and the superiority of antegrade (ACP) or retrograde (RCP) cerebral perfusion has not been shown. We examined the early and late outcomes for ACP versus RCP in proximal (hemi-) arch replacement using deep hypothermic circulatory arrest (DHCA).
\end{abstract}

\begin{abstract}
Methods: A retrospective analysis of a prospectively maintained database was performed for all patients undergoing elective and nonelective hemiarch replacement at a single referral institution from June 2005 to February 2013. Total arch cases were excluded to limit the analysis to shorter DHCA times and a more uniform patient population for whom clinical equipoise regarding ACP versus RCP exists. A total of 440 procedures were identified, with $360(82 \%)$ using ACP and $80(18 \%)$ using RCP. The endpoints included 30-day/in-hospital and late outcomes. A propensity score with 1:1 matching of 40 pre- and intraoperative variables was used to adjust for differences between the 2 groups.
\end{abstract}

Results: All $80 \mathrm{RCP}$ patients were propensity matched to a cohort of 80 similar ACP patients. The pre- and intraoperative characteristics were not significantly different between the 2 groups after matching. No differences were found in 30-day/in-hospital mortality or morbidity outcomes. The only significant difference between the 2 groups was a shorter mean operative time in the RCP cohort $(P=.01)$. No significant differences were noted in late survival $(P=.90)$.

Conclusions: In proximal arch operations using DHCA, equivalent early and late outcomes can be achieved with RCP and ACP, although the mean operative time is significantly less with RCP, likely owing to avoidance of axillary cannulation. Questions remain regarding comparative outcomes with straight DHCA and lesser degrees of hypothermia. (J Thorac Cardiovasc Surg 2014;148:2896-902)

See related commentary on pages $2902-4$.

Aortic arch surgery represents a technically demanding and high-risk cardiovascular operation. Given the mandatory period of cerebral ischemia inherent in the operation, subsequent neurologic dysfunction has been a concern. The reported incidence of adverse neurologic events after aortic arch surgery has ranged from $3 \%$ to $16 \% .{ }^{1}$ Consequently, attention has been focused on optimization of neuroprotective strategies. Hypothermia, usually by way of deep

From the Duke Center for Aortic Disease, Division of Cardiovascular and Thoracic Surgery, Department of Surgery, Duke University Medical Center, Durham, NC. Dr Ganapathi was supported by National Institutes of Health grant L30HL115769-01. Disclosures: Authors have nothing to disclose with regard to commercial support.

Received for publication Jan 15, 2014; revisions received March 17, 2014; accepted for publication April 8, 2014; available ahead of print June 6, 2014.

Address for reprints: G. Chad Hughes, MD, Duke Center for Aortic Disease, Division of Cardiovascular and Thoracic Surgery, Department of Surgery, Duke University Medical Center, Box 3051, Durham, NC 27710 (E-mail: gchad.hughes@duke. edu).

0022-5223/\$36.00

Copyright (c) 2014 by The American Association for Thoracic Surgery

http://dx.doi.org/10.1016/j.jtcvs.2014.04.014 hypothermic circulatory arrest (DHCA), has been used to minimize cerebral metabolic demand and protect cerebral tissue from ischemia and provide adequate neurologic protection during arch surgery. ${ }^{2-5}$ Although DHCA alone has been shown to be safe, most centers have used some form of adjunctive cerebral perfusion to minimize neurologic morbidity, particularly in cases requiring longer circulatory arrest times. The most common perfusion methods have been antegrade (ACP) and/or retrograde (RCP) cerebral perfusion, both popularized in the early 1990s. ${ }^{6,7}$ Both strategies have demonstrated adequate prevention of permanent neurologic dysfunction, although some studies have revealed an increased rate of transient neurologic dysfunction (TND) with RCP. ${ }^{5,8}$ However, the existing data have consisted primarily of voluminous observational studies without adequate control groups to provide robust clinical evidence. ${ }^{9}$ To date, a comparison of the 2 strategies head to head in a uniform patient population has not been conducted to truly determine whether either technique provides superior short- and long-term outcomes. Thus, the aim of the present study was to determine the comparative effectiveness of ACP versus RCP in the setting of DHCA in patients 

Abbreviations and Acronyms
$\mathrm{ACP}=$ antegrade cerebral perfusion
$\mathrm{CPB}=$ cardiopulmonary bypass
$\mathrm{DHCA}=$ deep hypothermic circulatory arrest
LOS = length of stay
$\mathrm{RCP}=$ retrograde cerebral perfusion
$\mathrm{TND}=$ transient neurologic dysfunction

undergoing elective and nonelective proximal (hemi-) arch replacement.

\section{METHODS \\ Patients and Data Source}

All patients undergoing elective and nonelective hemiarch replacement from June 2005 to February 2013 were identified using a prospectively maintained database at a single tertiary referral institution. All cases of total arch replacement were excluded to limit the analysis to shorter DHCA times and a more homogenous patient population for which clinical equipoise between ACP and RCP exists. ${ }^{10}$ All pre-, intra-, and postoperative variables were obtained from the Duke Thoracic Aortic Surgery Database, a prospectively maintained clinical registry of all patients undergoing thoracic aortic surgery at Duke University Medical Center (Durham, NC). After review and approval by the institutional review board of Duke University, the need for individual patient consent was waived. The query of the database identified 440 hemiarch replacements performed from June 2005 to February 2013. Of the 440 patients, 360 had undergone hemiarch replacement with ACP and 80 with RCP. The Society of Thoracic Surgeons definitions were used to define the patient comorbidities and postoperative outcomes. ${ }^{11}$ All patients received lifelong postoperative followup examinations at the Duke University Center for Aortic Disease. The Social Security Death Index (available at: http://ssdi.rootsweb.com/) was queried to confirm all deaths and survey patients lost to follow-up.

\section{Conduct of Procedures}

All patients included in the present study had undergone median sternotomy and replacement of the aortic root or supracoronary ascending aorta (with or without the aortic valve) with concomitant hemiarch replacement using DHCA, as previously described. ${ }^{12,13}$ Neurophysiologic intraoperative monitoring with electroencephalography was used to guide the degree of cooling in all elective operations and when available for the nonelective operations. A total of 358 cases $(81.4 \%)$ were monitored, as previously described. ${ }^{14,15}$ In brief, the patients were cooled until electrocerebral inactivity was reached, after which, DHCA was begun. Electrocerebral inactivity ensures maximal metabolic suppression of the brain and, therefore, maximal neurocerebral protection. ${ }^{15}$

Adjunctive cerebral perfusion began after opening of the aortic arch. ACP was the preferred adjunctive strategy early in the series, with RCP reserved for cases in which the right axillary artery was not suitable for cannulation owing to a small diameter or dissection of the vessel, as previously described. ${ }^{12}$ However, later in the series, RCP became increasingly used owing to the comfort of the team with the technique, especially in nondissection cases, and the perceived clinical equipoise regarding the outcomes compared with ACP (Figure 1).

For the ACP cases, the right axillary artery was cannulated with an 8-mm Dacron side graft, and ACP was performed with the base of the innominate and left common carotid arteries clamped and perfusion by way of the right axillary graft at a flow rate of 5 to $15 \mathrm{~mL} / \mathrm{kg} / \mathrm{min}$ and an inflow temperature of $12^{\circ} \mathrm{C}$ to a target right radial arterial line pressure of 50 to $70 \mathrm{~mm} \mathrm{Hg}$. For the $\mathrm{RCP}$ cases, a right-angled, long $26 \mathrm{~F}$ superior vena cava cannula was used with an average flow rate of 150 to $450 \mathrm{~mL} / \mathrm{min}$ at $12^{\circ} \mathrm{C}$ retrograde by way of the snared superior vena cava cannula to a target central venous pressure of $25 \mathrm{~mm} \mathrm{Hg}$. For the RCP cases, initial arterial cannulation for cardiopulmonary bypass (CPB) was most commonly by way of the distal ascending aorta, although the left axillary artery or femoral artery were occasionally used if necessitated by patient pathologic features or anatomy. In all cases, after completion of the hemiarch anastomosis, full flow CPB was reinstituted and the patient rewarmed after a 5-minute period of cold reperfusion for free radical washout.

\section{Outcomes}

The primary endpoint of the study was any neurologic complication, defined as any TND, transient ischemic attack, or clinical stroke. Clinical stroke was defined using The Society of Thoracic Surgeons definition as a new neurologic deficit persisting for $\geq 24$ hours. The secondary endpoints included 30-day/in-hospital mortality, composite 30-day/in-hospital major morbidity, operative time, the usual perioperative outcomes, and long-term survival. Composite 30-day/in-hospital major morbidity was defined using the standard Society of Thoracic Surgeons definition, including any reoperation, prolonged ( $>24$ hours) mechanical ventilation, acute renal failure (maximum postoperative creatinine $2 \times$ the baseline creatinine and $>2.0 \mathrm{~g} /$ $\mathrm{dL}$ ), new onset dialysis, or clinical stroke.

\section{Statistical Analysis}

All comparisons were made between the ACP and RCP groups on an intention to treat basis according to the cerebral perfusion strategy used. To create groups with a similar propensity to receive either ACP or RCP, a propensity score-matched analysis was conducted. Propensity scores for receiving ACP or RCP were calculated with the following characteristics: age, gender, race, patient comorbidities, New York Heart Association class, ejection fraction, presence of preoperative shock or malperfusion, previous aortic surgery, concomitant cardiac surgical procedures, procedural status, redo sternotomy, type of aortic procedure performed, procedural indication, preoperative rupture or cardiac tamponade, American Society of Anesthesiologists class, maximal aortic diameter, minimum nasopharyngeal temperature, circulatory arrest, CPB and crossclamp times, and use of electroencephalographic monitoring. The patients were matched using propensity scores in a 1:1 ratio. The balance of each covariate was assessed to ensure the model had been adequately specified. Categorical variables were compared using the chi-square test and continuous variables using Student's $t$ test. Kaplan-Meier survival analysis with the log-rank test after propensity matching was used for the long-term survival estimates. The significance levels were set at an $\alpha$ of 0.05 in all cases. Statistical analysis was performed using R, version 2.15.1 (R Project for Statistical Computing, R Foundation, Vienna, Austria).

\section{RESULTS}

The overall study population included 440 patients. ACP was used in 360 procedures $(81.8 \%)$ and RCP in 80 $(18.2 \%)$. Before adjustment, significant age and gender differences between the 2 groups were noted. Additionally, the prematch ACP patients tended to have an increased comorbid disease burden, including more hypertension $(82 \%$ vs $69 \% ; P=.01)$, tobacco abuse $(49 \%$ vs $31 \% ; P<.01)$, chronic obstructive pulmonary disease $(13 \%$ vs $5 \%$; $P=.03)$, and congestive heart failure (49\% vs $31 \%$; $P<.01$; Table 1). The prematch ACP cohort (Table 2) also included more nonelective operations $(30 \%$ vs $11 \%$; $P<.01)$, redo sternotomy ( $21 \%$ vs $5 \% ; P<.01)$, and acute or chronic dissection as the aortic pathologic entity $(32 \%$ vs $11 \% ; P<.01)$. The prematch ACP patients had also more 




FIGURE 1. Histogram demonstrating number of antegrade cerebral perfusion $(A C P)$ and retrograde cerebral perfusion $(R C P)$ hemiarch cases annually. (The data for 2013 included only patients treated before the study endpoint, February 2013).

commonly undergone concomitant root replacement $(40 \%$ vs $29 \% ; P=.04)$ and had a larger average maximal aortic diameter $(5.7 \mathrm{~cm}$ vs $5.3 \mathrm{~cm} ; P<.01)$.

Regarding the intraoperative variables (Table 3), before matching, the patients receiving RCP were more likely to have had intraoperative electroencephalographic monitoring $(94 \%$ vs $79 \% ; P<.01)$, consistent with a greater percentage of elective operations in the RCP group. Although the crossclamp times did not differ between the unadjusted groups, the RCP patients had shorter CPB times before matching (198 vs 216 minutes; $P<.01)$. The average minimum nasopharyngeal temperature did not differ between the unadjusted groups. A trend was seen toward a longer total DHCA time in the ACP group before matching (19.1 vs 17.9 minutes; $P=.06$ ), with no difference in the adjunctive cerebral perfusion times.

An unadjusted comparison of the outcomes (Table 4) did not reveal any differences in the occurrence of any neurologic complication (10.8\% ACP vs $7.5 \%$ RCP; $P=.36$ ), 30-day/ in-hospital mortality (3.6\% ACP vs $2.5 \% \mathrm{RCP} ; P=.61)$, or composite 30-day/in-hospital major morbidity (17.5\% ACP vs $15.0 \%$ RCP; $P=.59)$. The mean operative time was nearly 50 minutes longer in the ACP group (353.4 vs 308.3 minutes; $P<.01$ ), and the intraoperative use of factor VIIa was more predominant in the ACP group before matching. ${ }^{16}$

More specifically, regarding the primary study endpoint of any neurologic complication (TND, transient ischemic attack, or clinical stroke), approximately $10 \%$ of patients $(\mathrm{n}=45)$ in the entire cohort experienced $\geq 1$ neurologic complication. Of these, the vast majority $(\mathrm{n}=36)$ were TND, defined as any postoperative transient mental status change, including delirium or disorientation. Three patients experienced a transient ischemic attack, defined as a new neurologic deficit that had resolved completely within 24 hours. Finally, 13 patients $(3.0 \%)$ had clinical strokes, most of which presented as new motor deficits persisting for $>24$ hours. Of the 13 patients, 10 had imaging

TABLE 1. Patient demographics

\begin{tabular}{|c|c|c|c|c|c|c|}
\hline \multirow[b]{2}{*}{ Variable } & \multirow[b]{2}{*}{ Overall $(n=440)$} & \multirow[b]{2}{*}{$\operatorname{RCP}(\mathbf{n}=\mathbf{8 0})$} & \multicolumn{2}{|c|}{ Before matching } & \multicolumn{2}{|c|}{ After matching } \\
\hline & & & $\operatorname{ACP}(n=360)$ & $P$ value & $\operatorname{ACP}(n=80)$ & $P$ value \\
\hline Age (y) & $57.1 \pm 13.9$ & $50.9 \pm 13.7$ & $58.4 \pm 13.7$ & $<.01$ & $50.7 \pm 14.2$ & .46 \\
\hline Male gender & $300(68.2)$ & $46(57.5)$ & $254(70.6)$ & .03 & $50(62.5)$ & .52 \\
\hline White race & $335(76.1)$ & $67(83.4)$ & $268(74.4)$ & .07 & $66(82.5)$ & .83 \\
\hline Hypertension & $35(79.5)$ & $55(68.8)$ & 295 (81.9) & .01 & $60(75.0)$ & .38 \\
\hline Hyperlipidemia & $231(52.5)$ & $39(48.9)$ & $192(53.3)$ & .46 & $39(48.8)$ & .99 \\
\hline Tobacco abuse history & $202(45.9)$ & $25(31.3)$ & $177(49.2)$ & $<.01$ & $30(37.5)$ & .41 \\
\hline Diabetes & $40(9.1)$ & $11(13.8)$ & $29(8.1)$ & .13 & $5(6.3)$ & .11 \\
\hline CAD & $102(23.2)$ & $17(21.3)$ & $85(23.6)$ & .65 & $16(20.0)$ & .85 \\
\hline History of stroke or TIA & $28(6.4)$ & $3(3.4)$ & $25(6.9)$ & .26 & $1(1.3)$ & .31 \\
\hline COPD & $51(11.6)$ & $4(5.0)$ & $47(13.1)$ & .03 & $10(12.5)$ & .09 \\
\hline Baseline creatinine $>1.5 \mathrm{mg} / \mathrm{dL}$ & $46(10.5)$ & $6(7.5)$ & $40(11.1)$ & .32 & $6(7.5)$ & .99 \\
\hline PVD & $21(4.8)$ & $3(3.8)$ & $18(5.0)$ & .63 & $2(2.5)$ & .65 \\
\hline Previous MI & $29(6.6)$ & $4(5.0)$ & $25(6.9)$ & .51 & $2(2.5)$ & .41 \\
\hline $\mathrm{CHF}$ & $150(34.1)$ & $39(48.8)$ & $111(30.8)$ & $<.01$ & $36(45.0)$ & .63 \\
\hline NYHA class IV & $79(18.0)$ & $5(6.3)$ & $74(20.6)$ & $<.01$ & $7(8.8)$ & .94 \\
\hline $\mathrm{EF}(\%)$ & $53.0 \pm 5.8$ & $52.8 \pm 6.2$ & $53.0 \pm 5.8$ & .77 & $52.6 \pm 6.7$ & .83 \\
\hline Genetically trigged aortic condition* & $205(46.6)$ & $54(67.5)$ & $151(41.9)$ & $<.01$ & $53(66.3)$ & .87 \\
\hline Previous aortic surgery & $83(18.9)$ & $5(6.3)$ & $78(21.7)$ & $<.01$ & $7(8.8)$ & .55 \\
\hline
\end{tabular}

Data presented as mean \pm standard deviation or n (\%). RCP, Retrograde cerebral perfusion; $A C P$, antegrade cerebral perfusion; $C A D$, coronary artery disease; $T I A$, transient ischemic attack; $C O P D$, chronic obstructive pulmonary disease; $P V D$, peripheral vascular disease; $M I$, myocardial infarction; $C H F$, congestive heart failure; $N Y H A$, New York Heart Association; $E F$, ejection fraction. *Included patients with bicuspid aortopathy or connective tissue disorder. 
TABLE 2. Procedural characteristics

\begin{tabular}{|c|c|c|c|c|c|c|}
\hline \multirow[b]{2}{*}{ Variable } & \multirow[b]{2}{*}{ Overall $(n=440)$} & \multirow[b]{2}{*}{$\operatorname{RCP}(n=80)$} & \multicolumn{2}{|c|}{ Before matching } & \multicolumn{2}{|c|}{ After matching } \\
\hline & & & $\operatorname{ACP}(n=360)$ & $P$ value & $\operatorname{ACP}(n=80)$ & $P$ value \\
\hline Indication & & & & $<.01$ & & .99 \\
\hline Aneurysm & $315(71.6)$ & $71(88.8)$ & $244(67.8)$ & & $70(87.5)$ & \\
\hline Acute dissection & $91(20.7)$ & $6(7.5)$ & $85(23.6)$ & & $6(7.5)$ & \\
\hline Chronic dissection & $34(7.7)$ & $3(3.8)$ & $31(8.6)$ & & $4(5.0)$ & \\
\hline Maximal aortic diameter $(\mathrm{cm})$ & $5.6 \pm 1.0$ & $5.3 \pm 0.7$ & $5.7 \pm 1.0$ & $<.01$ & $5.5 \pm 0.9$ & .46 \\
\hline Rupture & $28(6.4)$ & $0(0.0)$ & $28(7.8)$ & $<.01$ & $0(0.0)$ & .99 \\
\hline Nonelective procedure status & $116(26.4)$ & $9(11.3)$ & 107 (29.7) & $<.01$ & $11(13.8)$ & .50 \\
\hline Redo sternotomy & $80(18.2)$ & $4(5.0)$ & $76(21.1)$ & $<.01$ & $6(7.5)$ & .51 \\
\hline Procedure performed & & & & .04 & & .86 \\
\hline Root replacement and hemiarch & $166(37.7)$ & $23(28.8)$ & $143(39.8)$ & & $24(30.0)$ & \\
\hline Ascending aortic replacement ( \pm AVR) and hemiarch & $274(62.3)$ & $57(72.2)$ & $217(60.3)$ & & $56(70.0)$ & \\
\hline Concomitant CABG & 77 (17.5) & $13(16.3)$ & $64(17.8)$ & .74 & $12(15.0)$ & .83 \\
\hline Concomitant valve repair or replacement & $30(6.8)$ & $8(10.0)$ & $22(6.1)$ & .24 & $6(7.5)$ & .58 \\
\hline ASA class 4 & $132(30.0)$ & $9(11.3)$ & $123(34.2)$ & $<.01$ & $10(12.5)$ & .96 \\
\hline
\end{tabular}

Data presented as mean \pm standard deviation or n $(\%) . R C P$, Retrograde cerebral perfusion; $A C P$, antegrade cerebral perfusion; $A V R$, aortic valve replacement; $C A B G$, coronary artery bypass grafting; ASA, American Society of Anesthesiologists.

confirmation with either computed tomography or magnetic resonance imaging. In 4 of the 13 cases $(31 \%)$ of clinical stroke, the strokes were massive and resulted in death.

After 1:1 propensity matching, the RCP and ACP groups did not demonstrate any significant differences in patient demographics, procedural characteristics, or intraoperative variables (Tables 1 to 3 ). Regarding the primary study endpoint (Table 4), the incidence of any neurologic complication was similar between the 2 matched groups $(11.3 \%$ ACP vs $7.5 \%$ RCP; $P=.42$ ). Furthermore, no significant differences were found in any 30-day/in-hospital outcomes (Table 4). The only significant difference that persisted between the 2 groups after matching was a shorter mean operative time in the RCP cohort, with RCP operations, on average, 30 minutes shorter (308.3 vs 338.3 minutes; $P=.01$ ). This difference was likely attributable to the avoidance of axillary cannulation and a greater use of central aortic cannulation in the RCP group. Kaplan-Meier analysis using only the matched patients did not reveal any significant differences in overall long-term survival $(P=.90$; Figure 2), which was confirmed by the last clinical followup examination and Social Security Death Index search.

\section{DISCUSSION}

Neuroprotection in aortic arch surgery is an important consideration given the mandatory period of cerebral ischemia required for repair. Although multiple strategies exist to minimize neurologic morbidity, comparative evidence regarding the optimal method of neuroprotection is lacking. ${ }^{9}$ The present study compared ACP and RCP in the setting of DHCA and demonstrated that an equivalent and acceptable safety profile can be achieved with either adjunctive perfusion technique during elective or nonelective aortic hemiarch surgery. Specifically, the incidence of major adverse neurologic events was low with either perfusion strategy.

Given the importance of neuroprotection, recent published data have called for a consensus regarding cerebral protection during aortic arch surgery, specifically pertaining to the optimal adjunctive cerebral perfusion strategy and patient temperature. ${ }^{10,17}$ Although a large body of published data has described the outcomes of arch surgery using either ACP or RCP, these studies have failed to provide strong data regarding the comparative effectiveness of each strategy. ${ }^{5,18-25}$ As highlighted in a recent publication

TABLE 3. Intraoperative variables

\begin{tabular}{|c|c|c|c|c|c|c|}
\hline \multirow[b]{2}{*}{ Variable } & \multirow[b]{2}{*}{ Overall $(n=440)$} & \multirow[b]{2}{*}{$\operatorname{RCP}(\mathbf{n}=80)$} & \multicolumn{2}{|c|}{ Before matching } & \multicolumn{2}{|c|}{ After matching } \\
\hline & & & $\operatorname{ACP}(n=360)$ & $P$ value & $\operatorname{ACP}(n=80)$ & $P$ value \\
\hline EEG monitoring & 358 (81.4) & 75 (93.8) & $283(78.6)$ & $<.01$ & $72(90.0)$ & .39 \\
\hline Crossclamp time (min) & $136.3 \pm 39.9$ & $131.0 \pm 44.2$ & $137.4 \pm 38.8$ & .23 & $129.2 \pm 34.4$ & .78 \\
\hline CPB time (min) & $212.9 \pm 48.7$ & $197.9 \pm 40.8$ & $216.2 \pm 49.7$ & $<.01$ & $208 \pm 59.8$ & .22 \\
\hline Minimum NP temperature $\left({ }^{\circ} \mathrm{C}\right)$ & $14.4 \pm 1.8$ & $14.5 \pm 1.8$ & $14.3 \pm 1.8$ & .56 & $14.2 \pm 1.8$ & .34 \\
\hline Circulatory arrest time (min) & $18.9 \pm 6.5$ & $17.9 \pm 4.3$ & $19.1 \pm 6.9$ & .06 & $17.7 \pm 6.4$ & .76 \\
\hline RCP time (min) & - & $15.5 \pm 4.2$ & NA & - & NA & - \\
\hline ACP time $(\mathrm{min})$ & - & NA & $15.0 \pm 5.8$ & - & $14.2 \pm 5.1$ & - \\
\hline
\end{tabular}

Data presented as mean \pm standard deviation or n (\%). RCP, Retrograde cerebral perfusion; $A C P$, antegrade cerebral perfusion; $E E G$, electroencephalographic; $C P B$, cardiopulmonary bypass; $N P$, nasopharyngeal; $N A$, not applicable. 
TABLE 4. Thirty-day/in-hospital outcomes

\begin{tabular}{|c|c|c|c|c|c|c|}
\hline \multirow[b]{2}{*}{ Variable } & \multirow[b]{2}{*}{ Overall $(n=440)$} & \multirow[b]{2}{*}{$\operatorname{RCP}(\mathbf{n}=\mathbf{8 0})$} & \multicolumn{2}{|c|}{ Before matching } & \multicolumn{2}{|c|}{ After matching } \\
\hline & & & $\operatorname{ACP}(n=360)$ & $P$ value & $\operatorname{ACP}(\mathbf{n}=80)$ & $P$ value \\
\hline Operative time (min) & $345.2 \pm 76.5$ & $308.3 \pm 72.7$ & $353.4 \pm 74.9$ & $<.01$ & $338.3 \pm 80.3$ & .01 \\
\hline Any neurologic complication* & $45(10.3)$ & $6(7.5)$ & $39(10.8)$ & .36 & $9(11.3)$ & .42 \\
\hline 30-d/In-hospital mortality & $15(3.4)$ & $2(2.5)$ & $13(3.6)$ & .61 & $3(3.8)$ & .65 \\
\hline 30-d/In-hospital major composite morbidity & $75(17.0)$ & $12(15.0)$ & $52(17.5)$ & .59 & $8(10.0)$ & .34 \\
\hline Any reoperation & $19(4.3)$ & $2(2.5)$ & $17(4.7)$ & .35 & $2(2.5)$ & .99 \\
\hline Reoperation for bleeding & $11(2.5)$ & $1(1.3)$ & $10(2.8)$ & .39 & $2(2.5)$ & .56 \\
\hline Intraoperative factor VIIa use & $105(23.9)$ & $10(12.5)$ & $95(26.4)$ & $<.01$ & $14(17.5)$ & .38 \\
\hline Postoperative factor VIIa use & $15(3.4)$ & $5(6.3)$ & $10(2.8)$ & .15 & $3(3.8)$ & .47 \\
\hline Prolonged ( $>24 \mathrm{~h}$ ) ventilation & $47(10.7)$ & $6(7.5)$ & $41(11.4)$ & .29 & $7(8.8)$ & .77 \\
\hline Acute renal failure $\dagger$ & $35(8.0)$ & $8(10.0)$ & $27(7.5)$ & .47 & $4(5.0)$ & .23 \\
\hline New onset dialysis & $9(2.0)$ & $2(2.5)$ & $7(1.9)$ & .76 & $3(3.8)$ & .65 \\
\hline TND & $36(8.2)$ & $6(7.5)$ & $30(8.3)$ & .24 & $5(6.3)$ & .75 \\
\hline Clinical stroke & $13(3.0)$ & $1(1.3)$ & $12(3.3)$ & .27 & $2(2.5)$ & .56 \\
\hline TIA & $3(0.7)$ & $0(0.0)$ & $3(0.8)$ & .27 & $3(3.8)$ & .08 \\
\hline 30-d Readmission & $48(10.9)$ & $7(8.8)$ & $41(11.4)$ & .48 & $13(16.3)$ & .15 \\
\hline Discharge to other than home & $28(6.4)$ & $3(3.8)$ & $25(6.9)$ & .26 & $2(2.5)$ & .65 \\
\hline Postoperative LOS (d) & $7.7 \pm 7.2$ & $6.9 \pm 5.5$ & $7.9 \pm 7.5$ & .15 & $7.6 \pm 9.8$ & .58 \\
\hline
\end{tabular}

Data presented as mean \pm standard deviation or $\mathrm{n}(\%)$. RCP, Retrograde cerebral perfusion; $A C P$, antegrade cerebral perfusion; TND, transient neurologic dysfunction; $T I A$, transient ischemic attack; LOS, length of stay. *Postoperative transient or permanent mental status change, TIA, or clinical stroke. $\dagger$ Maximum creatinine 2 times the baseline creatinine and $>2.0 \mathrm{~g} / \mathrm{dL}$

from the International Aortic Arch Surgery Study Group, the current arch surgery data consist mainly of observational studies without adequate control groups. ${ }^{9}$ The present report attempted to begin addressing this knowledge gap by directly comparing ACP to RCP in a uniform population and with a propensity-matched control group using matching for 40 pre- and intraoperative variables. The results we have presented demonstrate that for hemiarch surgery in the setting of DHCA, RCP offers neurologic, perioperative, and long-term outcomes equivalent to those with ACP.

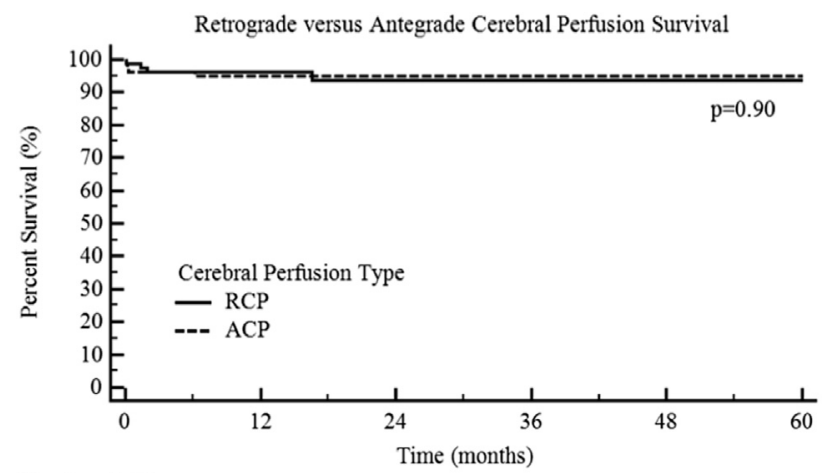

Number at risk

Group: RCP

Group: ACP

42

31

56

24

44

13

28

7

18

FIGURE 2. Kaplan-Meier curves comparing long-term survival of patients undergoing antegrade $(A C P)$ versus retrograde cerebral perfusion $(R C P)$.
We intentionally limited the study population to a more uniform group that included only hemiarch procedures, for which clinical equipoise regarding optimal adjunctive cerebral perfusion strategy clearly exists, ${ }^{17}$ because total arch procedures have been demonstrated to be an independent risk factor for adverse outcomes. ${ }^{1}$ Specifically, literature including total arch procedures introduces additional complexity of analysis since these procedures require longer periods of circulatory arrest, which is another risk factor for PND. ${ }^{26,27}$ Notably, the current study continues to demonstrate that excellent outcomes can be obtained utilizing DHCA for proximal arch replacement with one of the lowest incidences of neurologic dysfunction in the literature, an overall clinical stroke rate of $3 \%$, including $1.9 \%$ in elective cases.

Although permanent neurologic dysfunction has been the standard used to describe adverse neurologic events, the potential exists for subclinical neurologic events. ${ }^{12,28}$ Although the present study did not try to identify subclinical neurologic deficits, outcomes such as discharge to a destination other than home and the length of stay (LOS) might provide surrogates for subtle neurologic deficits, because patients with subclinical deficits might not be able to care for themselves, necessitating a longer LOS or institutional discharge. However, after propensity matching, no difference in discharge to a destination other than home or in the postoperative LOS was noted. Additionally, the occurrence of discharge to a facility was relatively low, $6.4 \%$ overall and $3.8 \%$ and $2.5 \%$ in the RCP and ACP groups, respectively, after matching. 
Similarly, the postoperative LOS was relatively brief, averaging just $>7$ days for all patients.

\section{Study Limitations}

The present study had some notable limitations. It was a single-institution, retrospective analysis with an associated inherent bias. Although we used a propensity-matched analysis to minimize treatment level biases, it could not adjust for all potential unknown bias. Our study was also notable because, before matching, no differences were found in the unadjusted postoperative outcomes, although the ACP patients were generally more ill. Thus, the comparisons that included only the matched patients, which represented a healthier patient population, might have underestimated the true risk of neurologic morbidity, particularly in older or sicker patients. Furthermore, the mean age of 51 years in the matched cohorts was somewhat younger than in previous reports of proximal aortic replacement, ${ }^{1}$ likely owing to a relatively large number of patients with bicuspid valve aortopathy or connective tissue disorder (107 of 160 total matched patients; 67\%) in the matched cohort. As such, the results might not be entirely generalizable to older patients with degenerative aortic aneurysms. Moreover, all operations were performed in the setting of a dedicated, high-volume, multidisciplinary aortic center; thus, the presented results might not be applicable to centers without these resources. The use of DHCA in all patients and the inclusion of only hemiarch procedures must also be acknowledged; thus, our results will not be applicable to moderate hypothermic circulatory arrest or total arch procedures, which necessitate longer circulatory arrest times. In addition, all cases used adjunctive cerebral perfusion; thus, no conclusions about the comparative effectiveness of DHCA alone can be made, although a recent meta-analysis suggested straight DHCA was associated with a greater stroke rate. ${ }^{29}$ Furthermore, our patients did not undergo a formal neurologic examination postoperatively by trained neurologists; thus, the potential for underestimation of subtle neurologic findings was present. Finally, the results of our study could not address the larger question of the optimal temperature for hypothermic circulatory arrest during aortic arch surgery. That will require larger studies such as those proposed by the International Aortic Arch Surgery Study Group ${ }^{9}$ to fully investigate this challenging question.

\section{CONCLUSIONS}

Aortic arch surgery presents a unique neurologic risk given the mandatory period of cerebral ischemia during surgery. We have demonstrated that with DHCA, equivalent outcomes can be achieved using either ACP or RCP in both the elective and nonelective setting. The decreased operative time with RCP might be advantageous from a cost perspective and provide potential benefit by minimization of the time in the operating room. Finally, although not the focus of our study, more evidence regarding the optimal temperature during arch replacement is essential for additional improvements in this challenging field of surgery.

\section{References}

1. Williams JB, Peterson ED, Zhao Y, O'Brien SM, Andersen ND, Miller DC, et al. Contemporary results for proximal aortic replacement in North America. J Am Coll Cardiol. 2012;60:1156-62.

2. McCullough JN, Zhang N, Reich DL, Juvonen TS, Klein JJ, Spielvogel D, et al Cerebral metabolic suppression during hypothermic circulatory arrest in humans. Ann Thorac Surg. 1999;67:1895-9; discussion 919-21.

3. Stecker MM, Cheung AT, Pochettino A, Kent GP, Patterson T, Weiss SJ, et al. Deep hypothermic circulatory arrest: I. Effects of cooling on electroencephalogram and evoked potentials. Ann Thorac Surg. 2001;71:14-21.

4. Hagl C, Ergin MA, Galla JD, Lansman SL, McCullough JN, Spielvogel D, et al Neurologic outcome after ascending aorta-aortic arch operations: effect of brain protection technique in high-risk patients. J Thorac Cardiovasc Surg. 2001;121: 1107-21.

5. Milewski RK, Pacini D, Moser GW, Moeller P, Cowie D, Szeto WY, et al. Retrograde and antegrade cerebral perfusion: results in short elective arch reconstructive times. Ann Thorac Surg. 2010;89:1448-57.

6. Kazui T, Inoue N, Yamada O, Komatsu S. Selective cerebral perfusion during operation for aneurysms of the aortic arch: a reassessment. Ann Thorac Surg. 1992;53:109-14.

7. Ueda Y, Miki S, Kusuhara K, Okita Y, Tahata T, Yamanaka K. Surgical treatment of aneurysm or dissection involving the ascending aorta and aortic arch, utilizing circulatory arrest and retrograde cerebral perfusion. J Cardiovasc Surg (Torino). 1990;31:553-8.

8. Okita Y, Minatoya K, Tagusari O, Ando M, Nagatsuka K, Kitamura S. Prospective comparative study of brain protection in total aortic arch replacement: deep hypothermic circulatory arrest with retrograde cerebral perfusion or selective antegrade cerebral perfusion. Ann Thorac Surg. 2001;72:72-9.

9. Yan TD, Tian DH, LeMaire SA, Misfeld M, Elefteriades JA, Chen EP, et al. The ARCH Projects: design and rationale (IAASSG 001). Eur J Cardiothorac Surg. 2014;45:10-6.

10. Englum BR, Andersen ND, Husain AM, Mathew JP, Hughes GC. Degree of hypothermia in aortic arch surgery —optimal temperature for cerebral and spinal protection: deep hypothermia remains the gold standard in the absence of randomized data. Ann Cardiothorac Surg. 2013;2:184-93.

11. Adult Cardiac Surgery Database Training Manual, v2.73, 2012 [cited 2013 June 14]. Available at: http://www.sts.org/sites/default/files/documents/Training Manual Update 8 12.pdf. Accessed October 6, 2013.

12. Lima B, Williams JB, Bhattacharya SD, Shah AA, Andersen N, Gaca JG, et al Results of proximal arch replacement using deep hypothermia for circulatory arrest: is moderate hypothermia really justifiable? Am Surg. 2011;77:1438-44.

13. Lima B, Williams JB, Bhattacharya SD, Shah AA, Andersen N, Wang A, et al Individualized thoracic aortic replacement for the aortopathy of biscuspid aortic valve disease. J Heart Valve Dis. 2011;20:387-95.

14. Husain AM, Ashton KH, Hughes GC. Thoracic Aortic Surgery. In: Husain AM ed. A Practical Approach to Neurophysiologic Intraoperative Monitoring. New York: Demos Medical Publishing; 2008:227-59.

15. James ML, Andersen ND, Swaminathan M, Phillips-Bute B, Hanna JM Smigla GR, et al. Predictors of electrocerebral inactivity with deep hypothermia. J Thorac Cardiovasc Surg. 2014;147:1002-7.

16. Andersen ND, Bhattacharya SD, Williams JB, Fosbol EL, Lockhart EL, Patel MB, et al. Intraoperative use of low-dose recombinant activated factor VII during thoracic aortic operations. Ann Thorac Surg. 2012;93:1921-8; discussion 1928-9.

17. Yan TD, Bannon PG, Bavaria J, Coselli JS, Elefteriades JA, Griepp RB, et al. Consensus on hypothermia in aortic arch surgery. Ann Cardiothorac Surg. 2013;2:163-8.

18. Misfeld M, Leontyev S, Borger MA, Gindensperger O, Lehmann S, Legare JF et al. What is the best strategy for brain protection in patients undergoing aortic arch surgery? A single center experience of 636 patients. Ann Thorac Surg. 2012; 93:1502-8.

19. Patel HJ, Nguyen C, Diener AC, Passow MC, Salata D, Deeb GM. Open arch reconstruction in the endovascular era: analysis of 721 patients over 17 years. J Thorac Cardiovasc Surg. 2011;141:1417-23.

20. Sugiura T, Imoto K, Uchida K, Minami T, Yasuda S. Comparative study of brain protection in ascending aorta replacement for acute type A aortic dissection: 
retrograde cerebral perfusion versus selective antegrade cerebral perfusion. Gen Thorac Cardiovasc Surg. 2012;60:645-8.

21. Svensson LG, Nadolny EM, Penney DL, Jacobson J, Kimmel WA, Entrup MH, et al. Prospective randomized neurocognitive and S-100 study of hypothermic circulatory arrest, retrograde brain perfusion, and antegrade brain perfusion for aortic arch operations. Ann Thorac Surg. 2001;71:1905-12.

22. Tanoue Y, Tominaga R, Ochiai Y, Fukae K, Morita S, Kawachi Y, et al. Comparative study of retrograde and selective cerebral perfusion with transcranial Doppler. Ann Thorac Surg. 1999;67:672-5.

23. Usui A, Miyata H, Ueda Y, Motomura N, Takamoto S. Risk-adjusted and casematched comparative study between antegrade and retrograde cerebral perfusion during aortic arch surgery: based on the Japan Adult Cardiovascular Surgery Database: the Japan Cardiovascular Surgery Database Organization. Gen Thorac Cardiovasc Surg. 2012;60:132-9.

24. Wiedemann D, Kocher A, Dorfmeister M, Vadehra A, Mahr S, Laufer G, et al. Effect of cerebral protection strategy on outcome of patients with Stanford type A aortic dissection. J Thorac Cardiovasc Surg. 2013;146:647-55.e1.
25. Williams ML, Ganzel BL, Slater AD, Slaughter MS, Trivedi JR, Edmonds HL, et al. Antegrade versus retrograde cerebral protection in repair of acute ascending aortic dissection. Am Surg. 2012;78:349-51.

26. Svensson LG, Crawford ES, Hess KR, Coselli JS, Raskin S, Shenaq SA, et al. Deep hypothermia with circulatory arrest: determinants of stroke and early mortality in 656 patients. J Thorac Cardiovasc Surg. 1993;106:19-28; discussion 31

27. Di Eusanio M, Wesselink RM, Morshuis WJ, Dossche KM, Schepens MA. Deep hypothermic circulatory arrest and antegrade selective cerebral perfusion during ascending aorta-hemiarch replacement: a retrospective comparative study. J Thorac Cardiovasc Surg. 2003;125:849-54.

28. Kumral E, Yuksel M, Buket S, Yagdi T, Atay Y, Guzelant A. Neurologic compli cations after deep hypothermic circulatory arrest: types, predictors, and timing. Tex Heart Inst J. 2001;28:83-8.

29. Tian DH, Wan B, Bannon PG, Misfeld M, Lemaire SA, Kazui T, et al. A metaanalysis of deep hypothermic circulatory arrest versus moderate hypothermic circulatory arrest with selective antegrade cerebral perfusion. Ann Cardiothorac Surg. 2013;2:148-58.

\title{
EDITORIAL COMMENTARY
}

\section{Brain protection in aortic arch surgery: Antegrade cerebral perfusion and retrograde cerebral perfusion need a tougher row to hoe}

\author{
John A. Elefteriades, MD, ${ }^{a}$ and Bulat A. Ziganshin, $\mathrm{MD}^{\mathrm{a}, \mathrm{b}}$
}

See related article on pages 2896-902.

The article in this issue of the Journal of Thoracic and Cardiovascular Surgery by Ganapathi and colleagues ${ }^{1}$ compares outcomes of aortic hemiarch replacement with antegrade cerebral perfusion (ACP) versus retrograde cerebral perfusion (RCP) in a large number of patients. Ganapathi and colleagues ${ }^{1}$ are to be congratulated for their superb clinical results and well-written study. They have contributed significantly to our body of knowledge with this work.

Important design characteristics of this study include the following:

- The 2 patient groups were very dissimilar initially, so propensity matching was applied to overcome this limitation.

From the Aortic Institute at Yale-New Haven Hospital, ${ }^{\text {a }}$ Yale University School of Medicine, New Haven, Conn; and Department of Surgical Diseases \#2, ${ }^{\mathrm{b}}$ Kazan State Medical University, Kazan, Russia.

Disclosures: Authors have nothing to disclose with regard to commercial support.

Received for publication Sept 15, 2014; accepted for publication Sept 15, 2014; available ahead of print Oct 11, 2014.

Address for reprints: John A. Elefteriades, MD, Aortic Institute at Yale-New Haven, 789 Howard Ave, CB-317, New Haven, CT 06510 (E-mail: john.elefteriades@ yale.edu).

J Thorac Cardiovasc Surg 2014;148:2902-4

$0022-5223 / \$ 36.00$

Copyright $(\odot) 2014$ by The American Association for Thoracic Surgery

http://dx.doi.org/10.1016/j.jtcvs.2014.09.041
- The operations were all hemiarch procedures, so the circulatory arrest times were all very short (generally less than 20 minutes).

- The study included both elective and emergency cases.

- The patients were quite young (mean age, 51 years).

- The ACP and RCP groups were cooled to an unusually low level $\left(<15^{\circ} \mathrm{C}\right)$.

This study provides useful data, solidifying the conventional wisdom that operations requiring less than $30 \mathrm{mi}-$ nutes of deep hypothermic circulatory arrest (DHCA) are safe regardless of modality of cerebral protection. In view of this point, this study is unlikely to change practice but rather affirms current principles.

The restriction to hemiarch operations is both a benefit and a liability. This restriction makes for an important element of uniformity among patients but at the same time limits the degree to which the findings can be generalized.

It is important to note that Ganapathi and colleagues ${ }^{1}$ delivered ACP only to one side of the brain through a right axillary cannula only. This is highly controversial because of the concern that ACP blood may not adequately reach regions remote from the right carotid artery, especially in case of an incomplete circle of Willis. Many experts advocate perfusion of both carotids, or even of both carotids and the left subclavian artery (to recruit the left vertebral artery as well). ${ }^{2}$ 